\title{
REFLEXÕES SOBRE LEITURA DE ILUSTRAÇÕES DE MODA A PARTIR DO SÉCULO XIX
}

Márcia Luiza França da Silva

Universidade Federal de Minas Gerais - EA-UFMG

marciafranca.designer@gmail.com

Marizilda dos Santos Menezes

Universidade Estadual Júlio de Mesquita Filho - FAAC/UNESP

zilmenezes@uol.com.br

Laís Regina Faganello

Universidade Estadual Júlio de Mesquita Filho - FAAC/UNESP

laisfaganello@hotmail.com

Lucimar Guimarães de Abreu

Universidade Federal de Minas Gerais - EA-UFMG

lucimar_g_abreu@hotmail.com

Resumo: O presente artigo procura analisar as ilustrações de modelos e modelagens dentro da história universal da Moda, pela ótica da comunicação com o usuário e com o profissional da costura, elaboradas por profissionais da confecção do vestuário sob medida. Um levantamento bibliográfico, com recorte a partir do século XIX, período marcado pelo desenvolvimento de métodos de modelagem e também de valorização dos ofícios, como alfaiates e modistas, possibilitou a identificação de um vasto número de ilustrações dentro desta trajetória, até a década de 1960. Dentre 143 obras relacionadas, 105 fazem referência à história da modelagem e 38 de cunho científico. Destas, nove foram selecionadas para ilustrar este ensaio, além do primeiro registro de livro de "desenvolvedor" identificado no ano de 1580, anterior ao período demarcado. A coleta de dados, que faz parte de uma disciplina de um doutorado, possibilitou um rico acervo tanto imagético quanto teórico, o que pode contribuir com inúmeros trabalhos de pesquisa, tanto no Design Gráfico, Editorial e de Moda.

Palavras-chave: História da moda, ilustração de moda, representação gráfica, vestimentas, modelagem.

Abstract: This article analyzes models and modeling illustrations within the universal history of Fashion Design. The work starts from the point of view of communication with the user and the sewing professional, prepared by professionals in the manufacture of clothing tailored. We consider titles of XIX century's literature about this issue. That period is marked by the 
development of modeling methods and appreciation of crafts, such as tailors and dressmakers. This allowed the identification of a large number of illustrations within this trajectory. Among 143 titles related, 105 of them refer to the history of modeling and 38 are about scientific publications. Considering this group, we selected nine titles to illustrate this essay, besides the first register, made by someone we named as a "developer" whose record book was identified in the year 1580, prior to the marked period. Data collection, which is part of a course within this doctorate program, has allowed a rich both imagistic and theoretical collection. This may contribute to numerous research papers, both in Graphic Design, Editorial and Fashion Design.

Keywords: history of fashion, fashion illustration, graphic representation, clothing, modeling.

\section{INTRODUÇÃO}

Na história universal da moda, pode-se observar a riqueza das ilustrações, tanto dos modelos criados, quanto de sua modelagem. O presente ensaio é fruto de um levantamento bibliográfico referente à história da moda e museus relacionados, dentro de uma disciplina de doutorado. Alguns resultados iniciais já tiveram sua publicação quanto à interpretação e experimentação de métodos. (REFERÊNCIA RETIRADA PARA REVISÃO CEGA). Aqui, as ilustrações recebem tratamento diferenciado, e têm suas reflexões na análise de suas complexidades.

A identificação dos materiais procurou as contribuições de vários autores, em diversos suportes disponíveis. O objetivo aqui é fazer um levantamento bibliográfico e imagético, e não se constitui em uma revisão bibliográfica sobre a história da moda ou da indumentária. A princípio, deparou-se com a pesquisa de Beduschi (2013) que elaborou importante linha cronológica da história do vestuário e da modelagem, servindo de norte para a busca bibliográfica do presente trabalho. Por ela, a abordagem teve como data inicial o século XIX para o estudo das ilustrações, uma vez que, no levantamento, esse período foi indicado como um marco rico em publicações.

Foram levantadas 143 bibliografias referentes à modelagem, alfaiataria e desenho de moda, do período que compreende os anos de 1886 a 1969. Muitas referências que contribuíram para a identificação das obras foram encontradas principalmente em Beduschi (2013), Thursfield (2001), Kidwell (1979), Puls (2003), Santos (2006), Pimenta (2008), Novaes (2011), Palma (2013), Carvalho e Linke (2013), Sobrino (2013), Escribano (2001), e Köhler (2011). Ainda assim, um volume excessivo indicado pelos pesquisadores não teve como ser acessado.

Este numeroso universo exigiu critérios de seleção. Iniciou-se por separar por autores, em seguida por tipo de publicação, reedições, e finalmente selecionar aquelas que mais colaborariam, no caso do presente artigo. O primeiro refinamento demonstrou que 105 foram de publicações referentes à história da modelagem e 38 eram de cunho científico, distribuídas entre artigos, dissertações, teses e periódicos. Das 105 históricas, um trabalho meticuloso e ainda não finalizado procurou relacionar 
épocas, estilos, modelos similares de vestimenta, contexto sócio-político. Dentro deste número, 22 são de âmbito nacional e quatro pertencem a desenvolvedores ${ }^{1}$.

Em cada autor, foi necessário fazer nova seleção das obras que pudessem colaborar com ilustrações mais ricas para o desenvolvimento da proposta. Apesar da citação da maioria delas, nem todas estão dispostas no presente estudo, devido ao volume de dados que foi levantado. E diante disso, apenas um número relativo de autores foi selecionado para esta análise. Nove compõem o presente artigo, sendo dois brasileiros.

Reflexões sobre leitura das ilustrações de moda a partir do século XIX são observações feitas sobre alguns desenvolvedores de métodos, cujas ilustrações de modelos e modelagens são vistas sob a ótica da comunicação com o usuário, no desenho detalhado de partes da vestimenta e de técnicas de representação que eles utilizavam tanto para o usuário (consumidores das vestimentas), quanto para o profissional da costura (alfaiates, modistas, costureiras).

\section{DESENVOLVIMENTO}

Em Beduschi (2013, p.21), a análise da linha cronológica disposta por ela tem importância significativa na delimitação deste trabalho, que data o século XIX, como o ponto de procura das bibliografias dentro da história da moda. Alguns trabalhos acadêmicos pontuam diversas referências, nas quais muitas imagens são redesenhadas para se obter um significado, como é o caso dos desenhos de Thursfield (2001). Iniciando as reflexões. Lipovetsky delimita o reconhecimento do que seria moda, ao afirmar que

[...] só a partir da Idade Média é possível reconhecer a ordem própria da moda, a moda como sistema, com suas metamorfoses incessantes, seus movimentos bruscos, suas extravagâncias. A renovação das formas se torna um valor humano, a fantasia exibe seus artifícios e seus exageros na alta sociedade, a inconstância em matéria de formas e ornamentações já não é exceção, mas regra permanente: a moda nasceu. (LIPOVETSKY, 2009, p.24).

Mesmo não estando no período demarcado, vale destacar aqui o que foi considerado o primeiro registro de livro de alfaiataria - "Libro de Geometria, Practica y Traça", editado em 1580. (Figura 1). A obra tem o formato landscape, mas em 1589, há o registro de uma segunda edição, em formato portrait. Ela trazia ilustrações de modelagens de vestimentas da época abrangendo desde o vestuário infantil, feminino, masculino, clero, uniformes da guarda e até mesmo para os animais (cavalaria). Também disponibiliza tabelas de medidas, métodos de manuseio e corte da matéria prima. Há se que notar a diagramação, o conceito de separação de assuntos por seções, além da proporção empregada nos desenhos e sua qualidade impecável, dados os recursos na época. (Figura 1). Tem destaque a "vara de medir", técnica de medição, o que poderia ser um antecessor das fitas métricas e dos métodos de se tomar medidas. (ALCEGA, 1580).

\footnotetext{
${ }^{1} \mathrm{O}$ termo foi adotado pela autora para designar profissionais, empresas e sistemas que desenvolveram métodos de modelagem, corte e costura. (n.d.a.)
} 

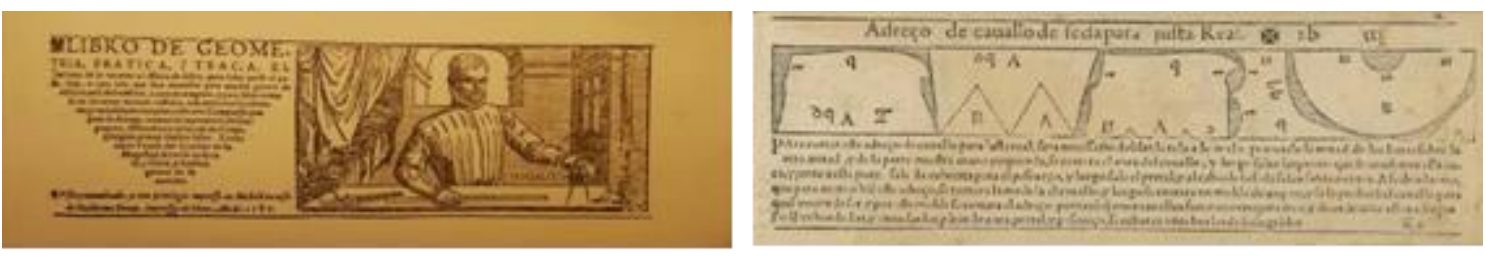

Figura 1: "Capa do Libro de Geometria, Practica y Traça e detalhe de modelagem de capa para cavalo da Ordem Real"

Fonte: Alcega (1580, i, 30)

Em Thursfield (2001), há uma modelagem de roupa masculina do século XV (Figura 2), o "joined-hose". Este foi o período que marcou o início de "moda", e a distinção de gênero. O leitor poderá observar que a ilustração não é uma imagem de época, mas é um desenho para o entendimento da vestimenta. As vistas frontal e posterior estão dispostas tridimensionalmente, como a indicar para o profissional os detalhes de uma modelagem complexa, diferentemente da maioria dos desenhos das atuais fichas técnicas da indústria do vestuário.
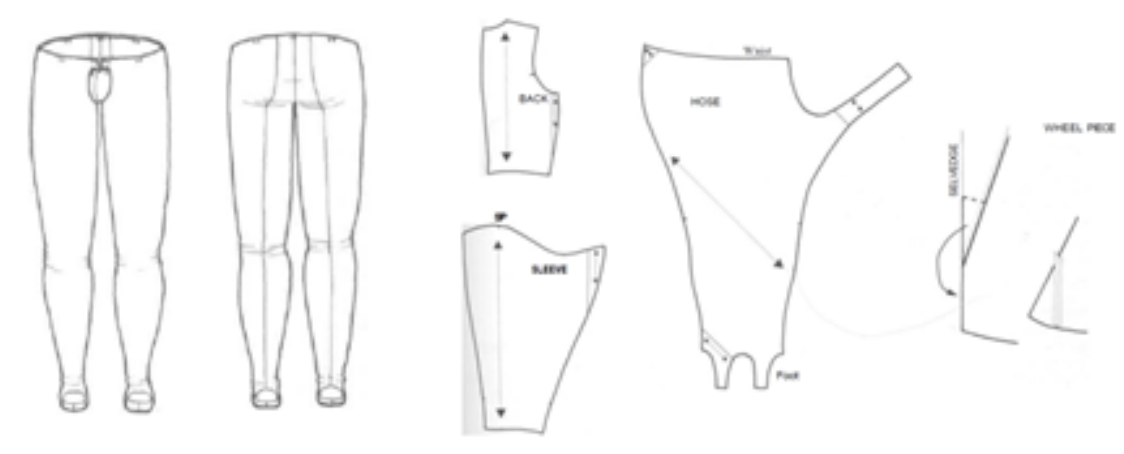

Figura 2: "Joined-hose - detalhes do modelo em vista frontal/posterior e modelagem da peça" Fonte: Thursfield (2001, p.110-112).

\subsection{Observações das Ilustrações}

Para as observações foram selecionados nove obras, em ordem cronológica, conforme seguem.

\subsubsection{Charles Kecklinger (1886)}

Charles Hecklinger ensinava o ofício de corte para alfaiates e costureiras, e decidiu publicar o seu método de modelagem, de forma condensada e de custo popular, para que costureiras e mães pudessem costurar para suas famílias. Segundo o autor, o método poderia ser aprendido em poucas horas, superior a qualquer outro até então conhecido. (HECKLINGER, 1886).

Numa obra pequena, em 50 páginas, percebe-se que os desenhos de modelos são de cunho artístico, ao passo que os de moldes têm sua complexidade. Sendo então de rápido aprendizado, os desenhos deveriam então ser de fácil compreensão. Como exemplo, a demonstração de tomada de medidas, o autora utiliza duas técnicas, como que uma colagem. As orientações são descritas minuciosamente, em texto. 
Na Figura 3, podem ser vistos modelos variados com o uso das anquinhas com a modelagem ao lado, mas com a descrição em texto corrido, e não como esquema. Os desenhos da modelagem possuem os textos indicativos muito próximos, o que pode dificultar a leitura, assim como sua tipologia. No entanto, não diferem em muito dos atuais desenhos de modelagem.

Na descrição de técnicas determinadas, os desenhos, mesmo que artísticos são, em sua maioria, elucidativos, conforme estão representados na Figura 4.

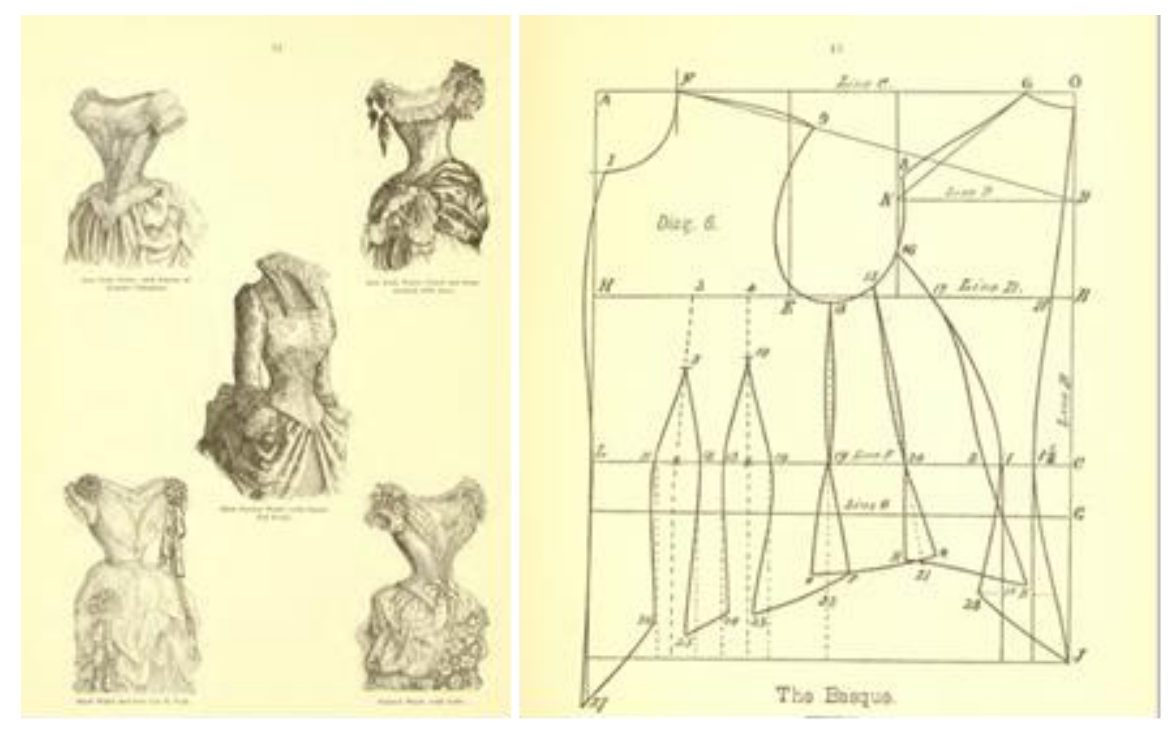

Figura 3 - "Desenhos de modelos de roupas femininas com a predominância das anquinhas, e o molde básico para a confecção".

Fonte: Hecklinger (1886, p.3).

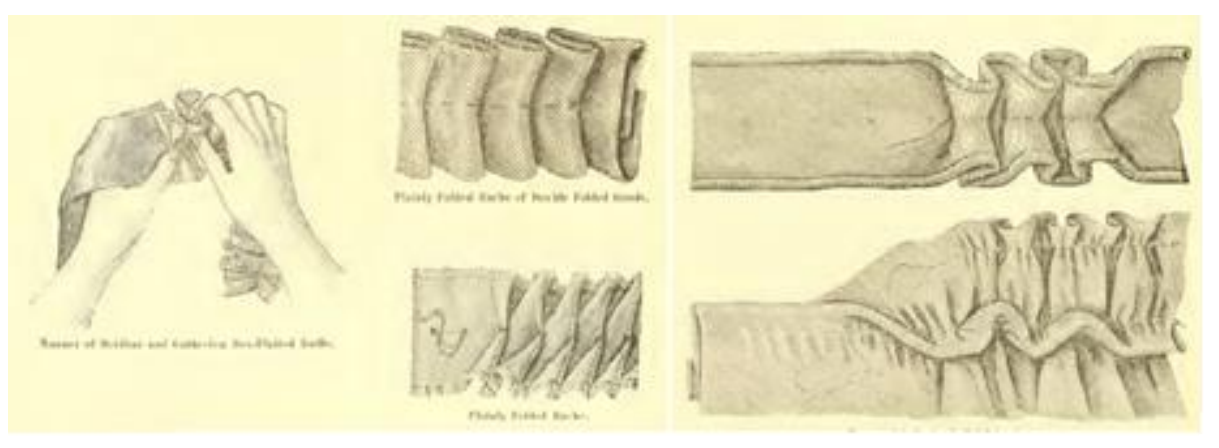

Figura 4 - "Detalhes de instruções para a confecção de babados e pregas" (imagens montadas para melhor compreensão).

Fonte: Hecklinger (1886, p.42).

\subsubsection{Hughes \& Storey (1892)}

Hughes \& Storey têm um aspecto, poderia ser dito, "especial". Seis anos apenas os separam de Hecklinger e, no entanto, eles utilizam técnicas diferenciadas e mais modernas e mais elucidativas para uma ilustração. A obra, igualmente pequena (44 páginas), não tem desenhos de modelos, mas apenas moldes em fundo negro, o que sugere contribuir para melhor compreensão de linhas e pontos, em destaque à folha impressa. Na Figura 5, constam os detalhes de uma montagem diferenciada de todas 
as pesquisadas até o final do recorte cronológico, o ano de 2013. O autor elabora o desenho do molde e, posteriormente anexa a fotografia da tela elaborada, inclusive com marcas de sua prova, na qual podem ser vistos os "amassados" do tecido.

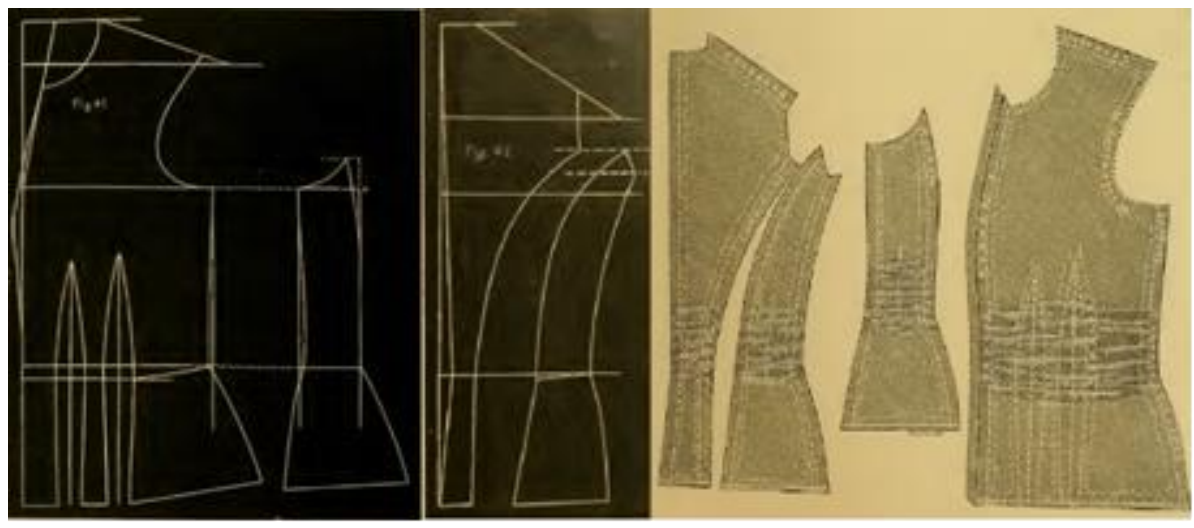

Figura 5 - "Moldes e tela de uma mesma peça de roupa" (Imagens montadas para melhor compreensão).

Fonte: Hughes \& Storey (1892, pp. 36-37).

\subsubsection{Eleganze Femminili (1911)}

A Revista Eleganze femminili foi publicada apenas no período de janeiro a maio de 1911, por assinatura. Ela apresentava as tendências dos estilistas famosos de Paris, Londres e Viena, eventos sociais, etiqueta, assuntos femininos, arte e história da moda. Os moldes poderiam ser adquiridos em musselina ou papel. O periódico era fonte de referência em tendências, tecidos, estilos e terminologia especializada da moda, em aproximadamente 20 páginas. As capas retratavam mulheres vestidas pelas casas de alta costura, e em cinco meses de edição, a revista discutiu aspectos relativos à modernidade, ao progresso, a temas polêmicos, como o uso da "jupe-culotte" (saiacalça) e das calças. O número 9 apontou para as dificuldades financeiras, ao publicar a cobrança das assinaturas, tendo no número 10 a última edição. Na figura 6 , o leitor poderá observar algumas capas.
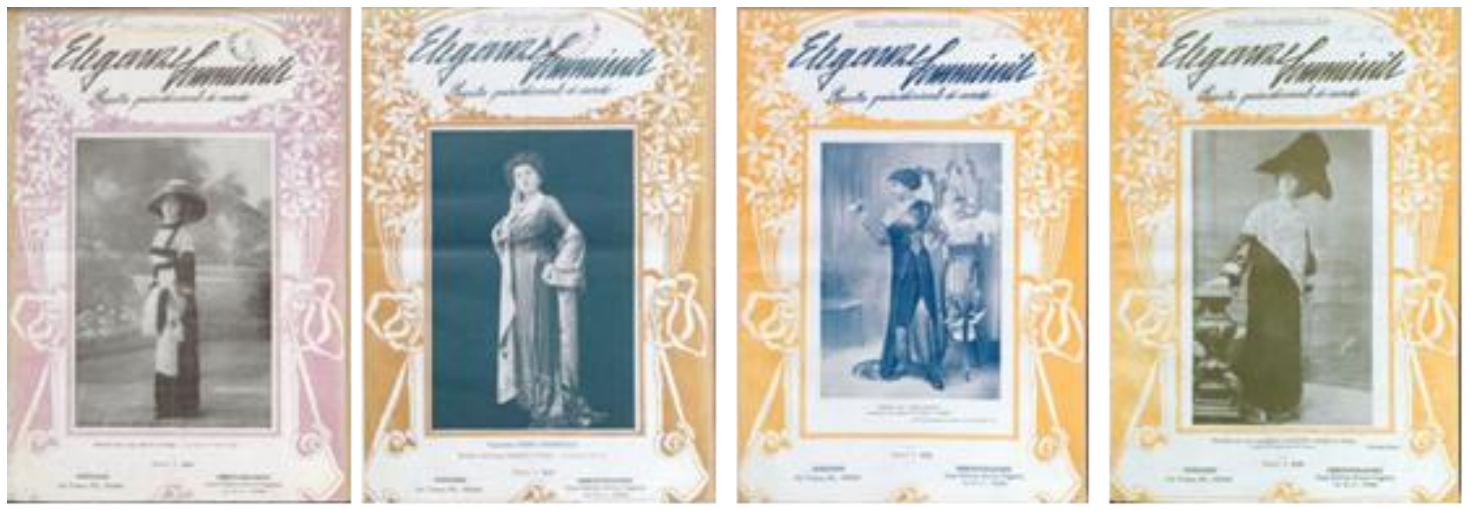

Figura 6 - "Revistas Elegance Femminilli - revista quindicinale di mode - 1911" Da esquerda para a direita $\mathbf{N}^{\text {o. }} \mathbf{1}$ e 2 (gennaio), e $\mathbf{N}^{\circ} \mathbf{7}$ e 8 (aprile).

Fonte: U.S.Library of Congress (2014, online). 
$\mathrm{Na}$ Figura 7, está a ilustração referente ao caso das jupe-cullote, tendo ao lado um modelo inspirado no vestuário greco-romano clássico como forma de protesto à novidade. Há o uso da fotografia retocada, e muitos modelos são desenhos artísticos.
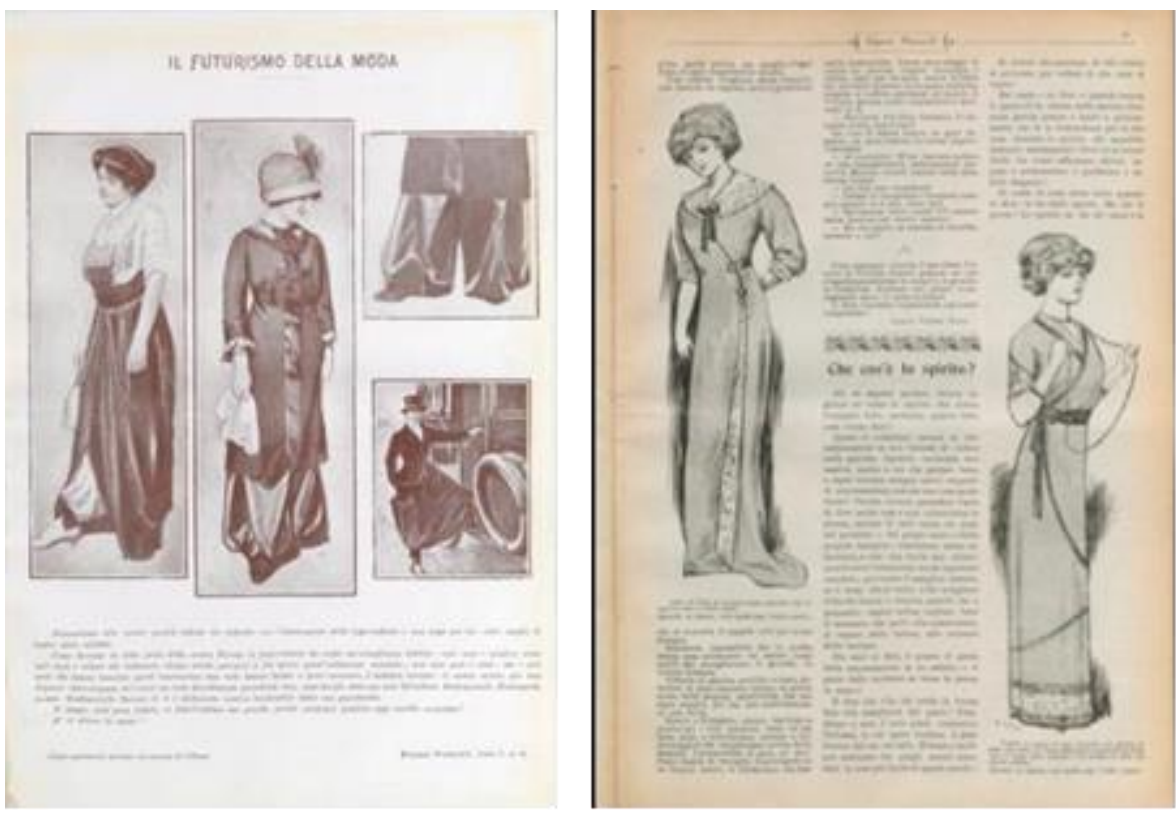

Figura 7 - "Revista Eleganze Femminilli

Da esquerda para a direita, tem-se o modelo "jupe-culotte" $N^{0 .} 4$, p. 18 . 0 apelo ao retorno dos modelos greco-romano clássicos, como retaliação à saia-calça $\left(\mathbf{N}^{\circ} \cdot 5, \mathbf{p} .12\right)$.

Fonte: U.S.Library of Congress (2014, online)

\subsubsection{W.D.F. Vincent (1898)}

Vincent, renomado professor de alfaiataria na School of Arts, foi o autor que mais se dedicou à área masculina, indo além da roupa comum, por atender a área militar, clérica e infantil, e feminina. Seu acervo é constituído de 13 partes, cada qual dedicada a modelos específicos de estilos. Na figura 8, estão dispostos desenhos dos modelos e seus respectivos moldes e de modelos de tesouras para trabalho. 0 desenho é preciso e detalhado, e parece demonstrar a preocupação do autor, pela impressão da tridimensionalidade, que o profissional tenha uma noção mais realística dos modelos, na execução do trabalho. Cabe ressaltar em seus trabalhos, a qualidade dos desenhos do instrumental necessário à confecção do vestuário.

\subsubsection{Mary Jane Rhoe (1918)}

Mary Jane Rhoe, antes de publicar seu livro, testou uma por uma, cada lição, revendo o que não estava correto. Desta forma, poderiam ser feitas sem qualquer dúvida. Ela dedicou seus trabalhos às escolas noturnas que ensinavam o ofício às modistas, no período da noite, que precisavam que as instruções fossem o mais simples possível. As lições não necessitavam da sequência disposta no sumário, e ao final de cada capítulo, havia um questionário que a aluna deveria responder, demonstrando seus conhecimentos, como numa instrução programada. Uma análise mais cuidadosa certifica que a obra é dedicada na íntegra, a acabamentos, tais como bolsos, bordados, maneiras de marcar os moldes. Os desenhos são simples, 
demonstrando claramente a posição de encaixes e indicações de letras e números não poluíam o desenho, acompanhado de instruções escritas (Figura 9).

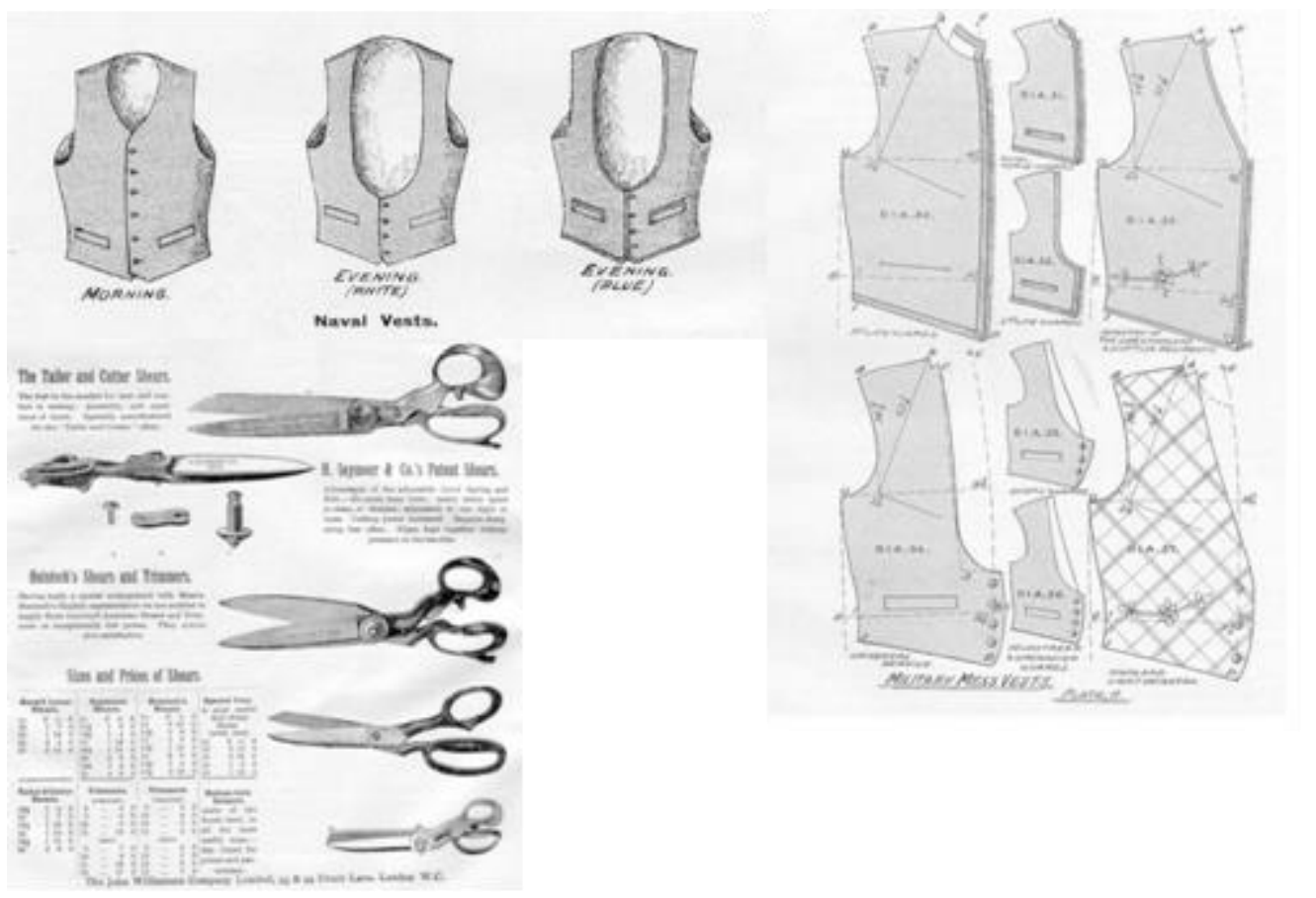

Figura 8 - "Acima, à esquerda, modelos de vestes militares, dispostos para manhã e noite em branco e azul, com moldes respectivos, à direita. Abaixo, os desenhos de tesouras

Fonte: Vincent (1902, pp.19, 20, extra-ads-8)

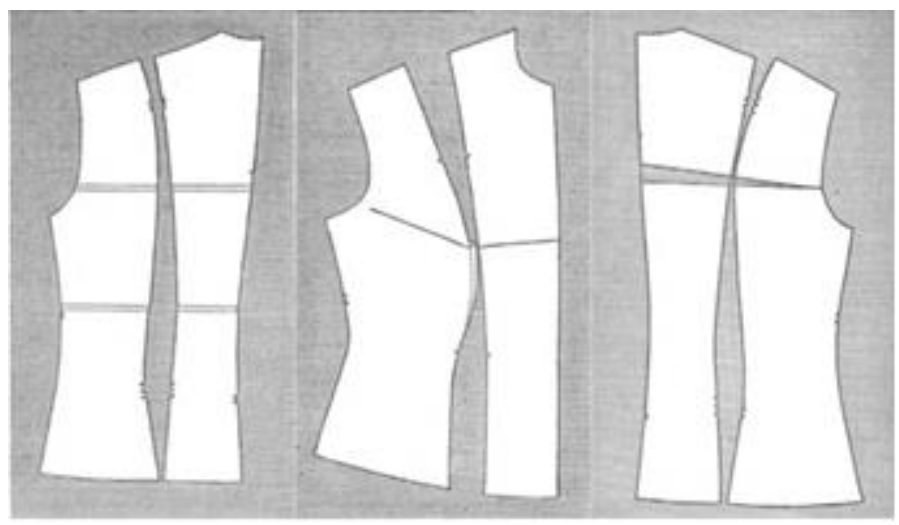

Figura 9 - "Exemplos de moldes alertando para o perfeito acabamento, 0 alinhamento de pences e cortes, além de marcações".

Fonte: Rhoe (1918, pp.6, 12, 14)

\subsubsection{Lutterloh Systems (1935)}

O sistema Lutterloh Systems teve seu início em 1935, na Alemanha, com a característica de produzir moldes em miniatura de modelos da época, que podiam ser utilizados em qualquer manequim, utilizando apenas as duas medidas do corpo, busto e quadril. $O$ que pode ser percebido é a evolução do desenho, mas não do corte, que foi evoluindo de acordo com as tecnologias para representação gráfica. Na figura 10, à esquerda, podem ser vistos os desenhos do modelo e do molde, em acabamento mais 
modesto, com a utilização de cor do tipo papel carbono, num tom azulado. Notar a composição do desenho, o enquadramento, como se o fundo do papel fosse uma porta na qual a modelo se apóia. À direita, podem ser observados os desenhos de modelos e moldes, em configurações da época da década (1969), com uso livre da cor, o que os tornam mais agradáveis e atraentes.
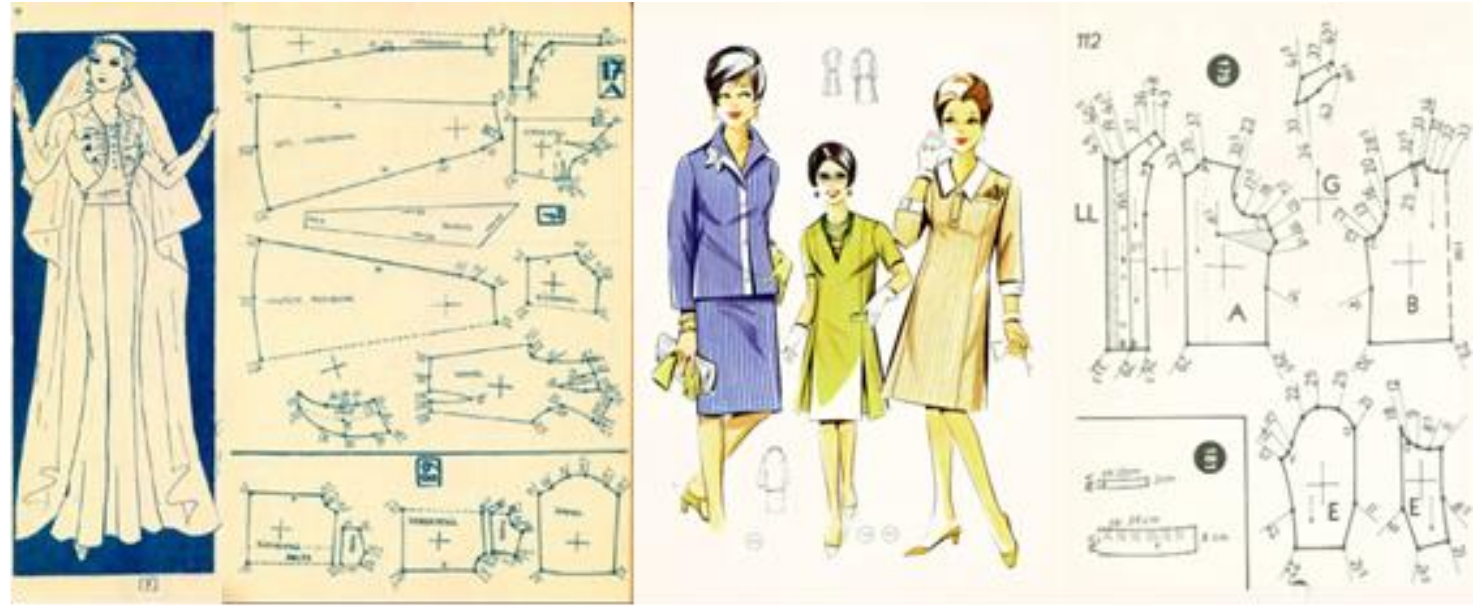

Figura 10 - "À esquerda Desenhos de Lutterloh, vestido de noiva, com modelagem, e à direita, modelos casual com modelagens".

Fonte: Lutterloh (1936, p. 4, 17-a); Lutterloh (1969, p. 93, 112)

\subsubsection{Gil Brandão (1967)}

Gil Brandão (1967) tem seus antecedentes na Medicina e na Arquitetura, o que o tornaram figura marcante na modelagem de então. Suas publicações trazem indicação de tabelas que descrevem medidas ideais e reais, relações entre elas, além de folgas variadas. $O$ autor dispõe orientações para o conhecimento geral da costura, com abordagens que vão desde a obtenção de medidas, até a prova e cálculos de tecidos. Cabe aqui destacar que o autor faz uso de uma linguagem dialogada em toda a publicação, rica de detalhes, inclusive de termos. É "uma sorte de aconselhamentos à leitora". Os desenhos das lições demonstram os traços de representações do desenho característico da Arquitetura, conforme se vê na Figura 11.
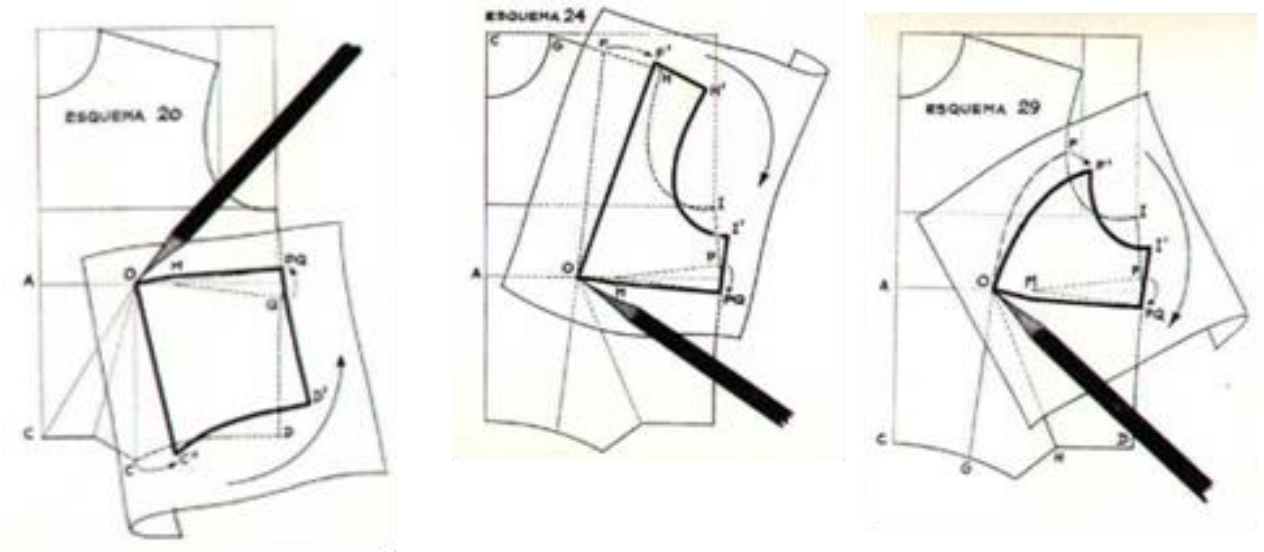

Figura 31 - "Esquemas relativos ao fechamento de pences". (nos quais podem ser percebidos traços de desenhos de representação técnica, talvez característicos da geometria descritiva. Da esquerda para a direita, esquema 20 pence horizontal; esquema 24 - pence de ombro; esquema 29 - pence curva da cava). Fonte: Brandão (1967, p. 41). 
Na edição de 1967, é importante destacar, no fechamento do curso, a lição 120 que propõe um exercício, representado na Figura 12, no qual a aluna deverá confeccionar, de acordo com um curto briefing,

[...] um três-peças composto de saia reta, com duas costuras na frente, um paletó meio apoiado na frente, sem gola, fechado por dois botões e um cintinho mole, cujo decote profundo deixa ver uma blusa interna, em mangas e com o decote composto por uma gola enrolada. (BRANDÃO, 1967, p. 190).

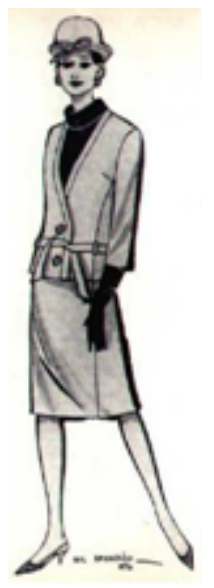

Figura 12 - "Representação do modelo como exercício proposto ao final das lições". Fonte: Brandão (1967, p. 190).

\section{CONCLUSÃO}

A identificação de representações de modelos e modelagens possibilitaria observar e analisar, com mais cuidado, o modo comunicativo e instrucional do produto com o usuário. Deste modo, foi possível observar que cada autor tem sua particularidade na representação da técnica da ilustração dos modelos e das respectivas modelagens, bem como sua evolução com o decorrer do tempo.

As referências de cunho científico foram importantes para nortear o levantamento bibliográfico e permitir novos pensamentos. A linha cronológica estabelecida por Beduschi (2013) é de grande valia por situar a história da Moda e permitir uma rápida visualização objetiva.

Os autores selecionados tinham como público alvo, pessoas iniciantes na prática, principalmente mulheres, que estudavam no período da noite, como complementar da renda familiar. Devido a isto, as ilustrações deveriam ser mais claras e didáticas. Nota-se uma característica artística na maioria dos trabalhos, e mesmo os autores com mais aptidão usavam de textos longos para completar as instruções.

O universo pesquisado é extenso, e no presente suporte, há uma delimitação que não permite a exposição de mais autores e mais exemplos imagéticos. Dessa forma, optou-se por autores mais relevantes, dentro o período estipulado. Um trabalho a ser desenvolvido poderia ser um cotejamento entre os autores, por época e estilos, tendo indícios para as mais diversas manifestações, como por exemplo, o uso de tipologia, tipos de papéis e representações gráficas versus os trabalhos de 
ilustração de moda dos períodos atuais, com as novas tecnologias e disponibilidade de materiais.

A pesquisa constitui um rico acervo tanto imagético quanto bibliográfico que pode contribuir para a formatação de trabalhos futuros com temáticas variadas bem como material para consultas posteriores.

\section{REFERÊNCIAS}

ALCEGA, J. Libro de geometria, practica y traça, el cual trata de la tocante ao oficio del Sastre. In.: U.S. LIBRARY OF CONGRESS. World Digital Library. Madri, Espanha, 2014. Disponível em <http://www.wdl.org/en/item/7333> Acesso em 20 jan. 2016.

BEDUSCHI, D. P. Diretrizes para o ensino de modelagem para o vestuário. 2013. $202 \mathrm{f}$. Dissertação (Mestrado em Ciências) - Escola de Artes, Ciências e Humanidades da Universidade de São Paulo. São Paulo, 2013.

BRANDÃO,G. Aprenda a costurar. ed. especial. Rio de Janeiro: Jornal do Brasil, 1967.

CARVALHO, M.H.R; LINKE, P.P. Gil Brandão: contribuições para a moda brasileira. In.: VI CONGRESSO INTERNACIONAL DE HISTÓRIA. Anais. 2013.

ESCRIBANO, R. D.L.P.Los tratados del arte del vestido em la españa moderna. AEA, $n$. 293, 2001. Disponível em <http://xn--archivoespañoldearte-

53b.revistas.csic.es/index.php/aea/article/viewFile/403/401> Acesso em 12 jan. 2016.

HECKLINGER,C. How to cute and make up ladie's garments: over 125 illustrations. New York:[s.n].1886. Disponível em: <https://pt.scribd.com/doc/33977976/1886Hecklinger-s-Ladies-Garments> Acesso em: 24 out. 2015.

HUGHES \& STOREY. The ladies' tailor: complete instructor. Saint Louis: Mekeel. 1892. Disponível em:

$<$ https://ia700408.us.archive.org/5/items/ladiestailorcomp00hugh/ladiestailorcomp00 hugh_bw.pdf> Acesso em: 30 out. 2015.

KIDWELL, C.B. Cutting a Fashionable Fit: dressmakers drafting systems in the United States. Washington, D.C: Smithsonian Institut Press, 1979. Disponível em:

$<$ http://pt.slideshare.net/SoraiaBevenuto/aprenda-a-costurar-por-gil-brando > Acesso em: 10 dez. 2015.

KÖHLER, C. História do vestuário. Tradução: Jefferson Luis Camargo. São Paulo: Martins Fontes, 2011.

LIPOVETSKY, G. $\mathbf{O}$ império do efêmero: a moda e seu destino nas sociedades modernas. Trad. Maria Lúcia Machado. 5. ed. São Paulo:Companhia das Letras, 2009.

LUTTERLOH PATTERN SYSTEM. Men's collection. Lindau: Verlag Lutterloh, 2000. Lutterloh, 1969.

.The golden rule: and its relation to the human body. Lindau: Verlag

. Der goldene Snitt. Lindau:Verlag Lutterloh, 1936.

NOVAES, M.A.F. Caminho das pedras: uma ressignificação do olhar e da experiência no processo de construção de roupas. 2011. 200f. Dissertação (Mestrado em Cultura Visual) - Faculdade de Artes Visuais da Universidade Federal de Goiás. Goiânia, 2011. 
PALMA, A. C. A modelagem através dos séculos e o início da moda. Modapalavra. Ano 6, n.11, jan-jun. 2013. E-periódico. [s.I.] [s.n.]. pp. 117-127.

PIMENTA, M. E. F. Memórias de alfaiates: significados de vida e trabalho. 2008. $286 f$. Dissertação (Mestrado em Gerontologia) - Faculdade de Ciências Médicas da Universidade Estadual de Campinas. Campinas, 2008.

PULS, L.M. Desenho de moda: paradigma para a construção de uma abordagem pedagógica. 2003. 125f. Dissertação (Mestrado em Engenharia de Produção) - Escola de Engenharia da Produção da Universidade Federal de Santa Catarina. Florianópolis. 2003.

REVISTA ELEGANZE FEMINILLI: revista quindicinale di mode. Ano 1.

n.1.2.3.4.5.6.7.9.10. Roma: Casa Editricio EuricoVerguera. 1911. U.S. LIBRARY OF CONGRESS. World Digital Library 2014. Disponível em:

<https://www.wdl.org/pt/item/> Acesso em 20 jan. 2016.

RHOE, Mary Jane. The dress you wear and how to make it. London: G.P. Putnam's Sons. 1918. Disponível em

<https://ia700400.us.archive.org/15/items/dressyouwearhowt00rhoe/dressyouwearh owt00rhoe.pdf> Acesso em: 22 out. 2015.

SANTOS, G.M.C. A roupa, a moda e a mulher na europa ocidental medieval: reflexões da opressão sofrida pela mulher na idade média (sec. XI-XV). 2006. 159f. Dissertação (Mestrado em Arte Contemporânea) Instituto de Artes da Universidade de Brasília. Brasília, 2006.

SOBRINO, L.V. Indumentaria masculina en la corte de Castilla a mediados del siglo XV: prendas de ir desnudo en la Cámara Real de Juan II el último año de su reinado.In.: Anales del Historia del Arte. vol. 23. num. especial. pp. 95-103. Universidad de Valladolid. 2013.

THE OXFORD ENGLISH DICTIONARY. Taillour. online. Disponível em <http://english.oxforddictionaires.com> Acesso em 20 jan. 2016.

THURSFIELD, S. Tailor's Assistant: making common garments 1200-1500. Carlton, Bedford: Ruth Bean Publishers, 2001.

U.S. LIBRARY OF CONGRESS. World Digital Library. Libro de geometria, practica y traça, el cual trata de la tocante ao oficio del Sastre. Madri, Espanha, 2014. Disponível em <http://www.wdl.org/en/item/7333> Acesso em 20 jan. 2016.

VINCENT, W.D.F. The cutter practical guide to cutting every kind of garments made by tailors. Part 1. London: John Willianson Co. Ltd. 1898. 